\title{
Editorial
}

\author{
Franzé Costa - Editor Chefe
}

\section{Prezados leitores}

Apresentamos à comunidade acadêmica o novo número da TPA, e chegamos com novidades que refletem um esforço de (re)alinhamento da Revista aos novos cenários e novas tendências acadêmicas do campo de Administração brasileiro e do Programa de Pós-Graduação em Administração (PPGA/UFPB), a unidade na qual a TPA está vinculada. Como anunciado anteriormente pelo professor Marcelo Bispo, assumimos a editoria desde julho de 2018, e temos implementado algumas mudanças que refletem esse realinhamento proposto.

A mudança central é na orientação da Revista, para a qual pretendemos 'fazer valer' o nome Teoria e Prática em Administração. 0 que vários autores que submetem artigos para a TPA têm recebido de questionamento, seja na etapa de desk review, seja na etapa de ajustes é o seguinte: de que forma o conhecimento geral pode contribuir para o aprimoramento da prática de profissionais de Administração? Em alguns casos, enfatizamos que nosso entendimento de 'profissionais de Administração' é amplo, e inclui executivos, líderes sociais e públicos, empreendedores, docentes e pesquisadores da área.

Nossa intenção é aproximar o conteúdo publicado do conceito que o PPGA tem debatido e, em grande medida, se orientado, qual seja, o conceito de um Programa de pós-graduação que, sem qualquer recuo no critério de rigor acadêmico, busca o complemento necessário da relevância acadêmica e profissional. Ou seja, levamos adiante o entendimento de que uma revista que, desde sua denominação, remete à 'teoria e prática', precisa assegurar, sempre, que o conhecimento veiculado traga uma indicação explícita seu valor teórico, mas também de seu valor prático. Com isso esperamos que os artigos publicados na TPA possam ser lidos por outros leitores que não apenas pesquisadores, podendo ser acessada também por profissionais de interesse não acadêmico e por docentes.

Além desses ajustes, fizemos uma alteração na 'equipe editorial', com a designação de um novo editor adjunto, o professor Pedro Jácome, que substituiu o professor Samir Adamoglu e designamos um Comitê editorial, composto por cinco professores do PPGA. Também iniciamos uma renovação do Conselho editorial e remodelamos o modelo de Editores associados, com a indicação de um número menor de colaboradores, cada um em alinhamento com as seis linhas editoriais que a revista passou a contar.

Foi nesse novo encaminhamento, que busca alinhar a revista com o momento presente e, principalmente, com o futuro, que seguimos nas avaliações das dezenas de submissões que foram recebidas. Dessas, chegaram ao final um total de onze textos (um artigo de opinião, nove artigos e dois casos para ensino), que são os que compõem esse número.

No primeiro artigo, intitulado Autoformação Política em Pesquisa Social: Intencionalidades Duradoras e a Prioridade do Local e de autoria dos professores Marcio Sá, Pedro Lincoln C. L. de Mattos, Amon Barros e Alessandra de Sá Mello da Costa, é feita uma reflexão a respeito do processo permanente de formação de pesquisadores e professores. 0 texto está desenvolvido em 4 ensaios, um de cada um dos autores que assinam o artigo completo.

0 segundo texto traz a pesquisa de Gilberto Sarfati, intitulado Entrepreneurship and the Face of Janus of Institutions: Stimulus Policies for High-Impact Entrepreneurs in Brazil and Russia, no qual o autor analisa o empreendedorismo em economias emergentes a partir de dois programas, um no Brasil e outra na Rússia. Já o terceiro artigo, de autoria de Michelle de Souza Rocha, Jane Kelly Dantas Barbosa, Letícia Rocha Guimarães e Kely César Martins de Paiva, intitulado Comprometimento Organizacional $e$ Percepções Temporais: Um Estudo sobre Jovens Trabalhadores, traz uma análise sobre o tema comprometimento e percepções temporais, a partir e um estudo empírico com jovens trabalhadores de Recife.

O quarto artigo, de autoria de José Alberto de Siqueira Brandão e Eduardo de Aquino Lucena, 
intitulado "Não, Tempo, não te gabarás de que eu mudo!" Evidências da Dimensão Temporal na Aprendizagem de Praticantes da Estratégia no Setor Público, aborda o tema aprendizagem organizacional no setor público, e traz um estudo qualitativo do "Pacto pela Educação em Pernambuco". 0 quinto artigo, A Imagem Corporativa e seus Reflexos: um Estudo de Imagem da Polícia Militar de Santa Catarina na Perspectiva de Moradores da Grande Florianópolis, segue ainda no campo da gestão pública. Neste, os autores Aline Regina Santos, Fabíola Gostek Pessôa e Ana Paula Grillo Rodrigues, desenvolvem um estudo quantitativo a respeito da imagem da Polícia Militar de Santa Catarina (PMSC), inovando por trazerem um tema relevante em Administração para um campo pouco abordado nos estudos gerenciais.

0 sexto artigo, intitulado $O$ Alinhamento entre a Teoria Ator-Rede e a Sociologia Relacional: uma Discussão Onto-Epistemológica para os Estudos Organizacionais, de autoria de Eduardo Guedes Villar e Karina De Déa Roglio, consiste em um debate de conteúdo metodológico, com proposta de uma aproximação de uma construção bem desenvolvida no campo disciplina da Sociologia para os estudos organizacionais. Ainda no campo temático de estudos organizacionais, temos o artigo Trabalho Docente e as Influências de Forças Coercitivas: um Estudo em uma Universidade Privada, de Carla Façanha, Mônica Tassigny, Marcos Lima e Fabiana Bizarria, que traz uma análise qualitativa a respeito das forças coercitivas sobre o trabalho docente, dimensionadas em governamentais, de mercado (o trabalho foi em uma IES privada) e do cliente.

Da categoria 'artigos', os dois últimos desse número são da área disciplinar de marketing: Concreto ou abstrato? Um esquema conceitual das representações mentais da economia compartilhada, de Jefferson Sordi, Maira Petrini e Claudio Hofmann Sampaio; e, Predisposição para Doação de Medula Óssea à luz da Teoria do Comportamento Planejado, de Pedro Coelho, Iveltyma Ibiapina, Áurio Lúcio Leocádio da Silva e Daniel Barboza Guimarães. O primeiro tem caráter mais ensaístico e aborda o tema da economia compartilhada, e o segundo traz uma pesquisa empírica, de orientação quantitativa, que resgata o tema da doação de medula óssea a partir da perspectiva de marketing social.

Mantendo a tradição da revista de contribuir também com profissionais e Administração que atuam como docentes, fechamos o número com dois casos para ensino. No primeiro deles, intitulado Mobilidade do Aeroporto Internacional Governador Aluízio Alves, de autoria de Thaiana Coelho Monteiro Fernandes, Maria Valéria Pereira de Araújo, Andréa do Nascimento Barbosa Cacho, Iranilton Marcolino Pereira e Maria Isabel de Medeiros Brito, é ilustrada a situação-problema envolvendo as questões de mobilidade no Aeroporto Internacional Governador Aluízio Alves, no Rio Grande do Norte, analisando ajustes, conflitos e decisões relevantes. 0 segundo caso, e último texto desse número, tem autoria de Charles Agostini, Raul Beal Partyka e Jeferson Lana, com o título de Previsão de Vendas e Dados Estatísticos: o Caso da Woodstock e suas Exportações para os EUA, e trata de um tema relevante para a formação de administração, que é a utilização de métodos estatísticos preditivos para suporte à decisão gerencial.

Esperamos que os artigos alcancem o público da TPA e que contribuam para pesquisas, exercícios docentes, realização de trabalhos acadêmicos e aplicados e, principalmente, que sejam úteis para refletir a Teoria e a Prática em Administração. Desejamos a todos uma boa leitura. 